Revista Brasileira de Odontologia Legal - RBOL

\title{
Biossegurança
}

\section{CONHECIMENTOS DE BIOSSEGURANCCA PARA AS PRINCIPAIS ATIVIDADES DE RISCO ENVOLVENDO SERVIDORES PÚBLICOS, DISCENTES E EMPREGADOS DA LIMPEZA DO CURSO DE ODONTOLOGIA DA UFVJM/DIAMANTINA*}

\section{Biosafety knowledge for the main risk activities involving public servers, students and cleaning staff of the dentistry course of UFVJM/Diamantina}

\author{
Anna Catharina Vieira ARMOND', Patrícia Furtado GONCCALVES ${ }^{2}$, Olga \\ Dumond FLECHA ${ }^{2}$, Dhelfeson Willya Douglas de OLIVEIRA ${ }^{3}$, Fábio Coelho \\ SAMPAIO ${ }^{4}$, Saulo Gabriel Moreira FALCI ${ }^{5}$. \\ 1. Mestranda em Clínica Odontológica UFVJM, Diamantina, MG, Brasil. \\ 2. Professora associada do departamento de Odontologia, FCBS - UFVJM, Diamantina, MG, Brasil. \\ 3. Doutorando em Odontologia - UFMG, Belo Horizonte, MG, Brasil. \\ 4. Professor Adjunto do departamento de Farmácia - UFVJM, Diamantina, MG, Brasil. \\ 5. Professor Adjunto do departamento de Odontologia - UFVJM, Diamantina, MG, Brasil. \\ * Trabalho de Conclusão de Curso, como parte dos requisitos exigidos para a conclusão do curso de Odontologia da \\ UFVJM/Diamantina.
}

Informação sobre o artigo

Recebido: 25 Maio 2016

Aceito em: 30 Jun 2016

\author{
Autor para correspondência \\ Anna Catharina Vieira Armond \\ Universidade Federal dos Vales do Jequitinhonha e \\ Mucuri - Campus JK, Departamento de Odontologia. \\ Rua da Glória, 187. Centro. 39100-000 - Diamantina, MG. \\ Email: annarmond@gmail.com.
}

\section{RESUMO}

Introdução: Biossegurança é um tema fundamental na odontologia considerando os procedimentos em que o profissional e a equipe de trabalho entram em contato com secreções da cavidade oral, potencialmente contaminantes. Objetivo: Avaliar o conhecimento de biossegurança dos servidores, discentes e empregados da limpeza responsáveis pelas clínicas e laboratórios do curso de Odontologia da UFVJM. Metodologia: Foi realizada uma pesquisa quali-quantitativa, utilizando quatro questionários validados, um para cada grupo-alvo dos envolvidos. Resultados: No total, foram avaliados questionários respondidos por 156 discentes, 17 técnicos, 19 docentes e 7 empregados da limpeza. Observa-se que $84,2 \%$ dos docentes abordam o tema biossegurança, entretanto, $31,6 \%$ dos docentes consideram que os alunos não são conscientes sobre biossegurança. 42,9\% dos funcionários da limpeza não sabem o que é biossegurança, $100 \%$ não receberam nenhuma capacitação e gostariam de receber mais informações. Dentre os técnicos do Departamento de Odontologia, $64,7 \%$ não receberam treinamento prévio e somente $11,8 \%$ recebem treinamento periódico para prevenção de acidentes. Dentre os discentes, $48,7 \%$ consideram que o ensino é insuficiente para uma prática clínica segura, 17,9\% não usam EPI completo, $55,8 \%$ dos alunos não saberiam se portar diante a um acidente com material contaminado, apesar de 25,6\% relatarem que já sofreram algum acidente. Conclusão: A abordagem pedagógica sobre 
biossegurança no curso de Odontologia deve ser revista para capacitar melhor os alunos e diminuir a distância entre o conhecimento teórico e a prática. É necessário investir em capacitação de toda a equipe de profissionais envolvidos no curso de Odontologia.

\section{PALAVRAS-CHAVE}

Odontologia Legal; Biossegurança; Riscos Ambientais.

\section{INTRODUÇÃO}

A biossegurança consiste no conjunto de ações voltadas para a prevenção, minimização ou eliminação de riscos inerentes às atividades de pesquisa, produção, ensino, desenvolvimento tecnológico e prestação de serviços, que podem assim comprometer a saúde do homem, dos animais, do meio ambiente ou a qualidade dos trabalhos desenvolvidos ${ }^{1}$.

No Brasil, a biossegurança possui duas diferentes vertentes de abordagem. A primeira, chamada de biossegurança legal, começou a ser discutida no final da década de 1980, sob influência das iniciativas internacionais. No entanto, somente após a proposta da Lei da Biossegurança ${ }^{2}$ a construção do conhecimento e aplicação na prática se iniciou realmente ${ }^{3}$. Entretanto, a Lei № $8974 / 95$ foi revogada, estando vigente a Lei № 11.105 de 24 de março de $2005^{4}$ que trata das questões envolvendo a manipulação de organismos geneticamente modificados e pesquisas de células-tronco embrionárias ${ }^{5}$.

A outra vertente envolve os riscos relacionados com agentes químicos, físicos, biológicos, ergonômicos e psicossociais, chamada biossegurança praticada. Ela é desenvolvida principalmente em instituições de saúde, dentro do contexto de segurança ocupacional. A biossegurança praticada está apoiada na legislação de segurança e saúde ocupacional (Lei № 6514/1977), principalmente nas Normas Regulamentadoras - NRs, do Ministério do Trabalho e Emprego (Portaria № 3214/1978), Lei Orgânica de Saúde (№ 8080/1990), Lei de Crimes Ambientais (№ 9605/1998), Resoluções da Agência Nacional de Vigilância Sanitária (ANVISA) e Conselho Nacional de Meio Ambiente (CONAMA) ${ }^{5}$.

Segundo Pereira et al. $(2010)^{3}$, a primeira produção científica sobre biossegurança na área da saúde, no Brasil, ocorreu em 1989. A partir daí, desenvolveram-se principalmente nas instituições de saúde, envolvendo os riscos por agentes químicos, físicos, biológicos, ergonômicos e psicossociais, baseando-se em diversas legislações que, infelizmente, nem sempre foram respeitadas.

Dentre os agentes biológicos destacam-se as doenças infectocontagiosas que têm estimulado pesquisas sobre acidentes ocupacionais e biossegurança entre profissionais da saúde de diferentes países. Um dos fatos mais marcantes foi $o$ reconhecimento do primeiro caso de aquisição da Síndrome da Imunodeficiência Adquirida (SIDA) por acidente ocupacional, que ocorreu com uma enfermeira, a atenção dos profissionais da saúde para medidas preventivas e medidas de biossegurança se intensificou $^{6}$. No Brasil, o primeiro caso de SIDA adquirido de maneira ocupacional só foi reconhecido pelo Ministério do Trabalho 
em 1999, acometendo uma auxiliar de enfermagem que colaborava no procedimento de punção venosa ${ }^{7}$.

Entretanto, não só a SIDA se destaca como uma importante doença possível de ser adquirida como acidente ocupacional, as hepatites virais também se encontram entre as doenças mais passíveis de transmissão. As hepatites virais se dividem em dois grupos na forma de contágio, a forma fecal-oral (vírus $\mathrm{A}$ e E) e a forma sanguínea (vírus $B, C$ e $D)^{8}$. As hepatites HBV e HCV podem ser contraídas por trabalhadores da área da saúde através da exposição ocupacional ${ }^{9}$. O risco médio de se adquirir 0 vírus HIV é de, aproximadamente, 0,3\%. A probabilidade de infecção pelo vírus da hepatite $B$ é significativamente maior podendo atingir até $40 \%$, e para o vírus da hepatite C o risco pode variar de 1 a $10 \%{ }^{10}$.

\section{Especificamente sobre a} biossegurança praticada na Odontologia, verifica-se que esta área deve ser estudada por todos os que exercem a profissão, de modo direto ou indireto, e ainda por aqueles que podem entrar em contato com o material biológico potencialmente contaminado oriundo dos atendimentos odontológicos. A justificativa deve-se ao fato do grande número de procedimentos em que o profissional está exposto quando atua na cavidade oral, como saliva e sangue, além dos aerossóis, que coloca a Odontologia como uma das áreas de maior risco de ocorrência de acidentes ocupacionais $^{11,12}$. Além do manejo frequente de instrumentos perfurocortantes, como bisturis e agulhas de anestesia, o uso da caneta de alta rotação para remoção de tecido dental ou materiais restauradores produz uma grande quantidade de partículas em suspensão que atingem 0 cirurgião dentista e o auxiliar. De acordo com Gir et al. (2008) ${ }^{9}$ dentre os estudantes da área da saúde, os graduandos em Odontologia são os mais acometidos por acidentes perfurocortantes.

Dentro dos riscos biológicos existem ainda as doenças transmitidas pelas vias aéreas, sendo as principais, rubéola, sarampo, doença meningocócica, gripe e tuberculose, que podem ser evitadas com medidas de biossegurança. E, finalmente, as doenças transmitidas pelo contato direto ou indireto com os pacientes, como herpes simples, escabiose ou sarna, piolho, micose e a conjuntivite ${ }^{13}$.

Além dos alunos, outros profissionais estão sujeitos às normas de biossegurança dentro das clínicas e laboratórios universitários, como os técnicos administrativos, professores e os funcionários de limpeza das clínicas. Em uma análise qualitativa feita por Pinelli et al. $(2011),{ }^{14}$ observaram que a maioria dos alunos de Odontologia consideram que os protocolos de biossegurança são pouco práticos e que grande parte dos alunos se queixa dos exemplos dos docentes e funcionários.

Em um estudo realizado por Canini et al. $(2005)^{15}$, relatou-se que dentre os funcionários que atuavam em serviços de suporte hospitalar, os auxiliares da limpeza foram os mais envolvidos em acidentes e, na maioria dos casos, os acidentes foram causados por agulhas descartadas em local impróprio. A partir disso, evidencia-se a grande necessidade de capacitação da 
equipe de limpeza e reitera-se a importância da prática de biossegurança pelos profissionais da saúde como um todo.

Em uma revisão feita por Bezerra et al. $(2014)^{16}$, sobre a produção científica de biossegurança na odontologia, os estudos analisados evidenciaram que 0 conhecimento e as medidas adotadas para redução de riscos e biossegurança não são suficientes para garantir proteção da equipe e dos pacientes.

Visto isso, o presente estudo tem como objetivo avaliar o conhecimento de biossegurança dos servidores públicos (docentes e técnicos), discentes e empregados da limpeza responsáveis pelas clínicas e laboratórios do curso de Odontologia da UFVJM/Diamantina.

\section{MATERIAIS E MÉTODOS}

Foi realizada uma pesquisa qualiquantitativa para avaliar os conhecimentos de biossegurança para as principais atividades de risco envolvendo servidores públicos (docentes e técnicos), discentes (estudantes) e empregados responsáveis pela limpeza do curso de Odontologia do Campus I da UFVJM/Diamantina. Para isso, foram utilizados quatro questionários, um para cada grupo-alvo dos envolvidos. O trabalho foi submetido ao Comitê de Ética em Pesquisa da UFVJM (CEP/UFVJM) ${ }^{17}$ que apresentou o parecer favorável sob o número de protocolo 017/12 em 24 de abril de 2012. Numa segunda etapa, os questionários foram entregues para os professores efetivos que ministram aula no curso de Odontologia, técnicos do departamento de Odontologia, empregados responsáveis pela limpeza (terceirizados) e estudantes do curso de Odontologia (matriculados entre o primeiro e 0 nono período do curso).

Todos os indivíduos considerados público-alvo, respeitando os pré-requisitos determinados, foram convidados para responder os questionários durante os meses de julho e agosto de 2013. Foram entregues, junto com os questionários, os TCLE (Termo de Consentimento Livre e Esclarecido). Foram excluídos os alunos que não estivessem regularmente matriculados dentro dos períodos prédeterminados no curso, participantes com idade menor que 18 anos e indivíduos que não quisessem assinar o TCLE.

Os questionários foram instrumentos fechados, adaptados para cada grupo-alvo, de autopreenchimento, anônimos e não vinculados ${ }^{18}$. Tais questionários abordavam conhecimentos sobre biossegurança praticada relativa à(ao): uso de equipamentos de proteção individual (EPI), ocorrência de acidente de trabalho, reencape de agulha, risco de transmissão ocupacional, realização de teste sorológico para Hepatite $B$, vacina contra Hepatite $B$, procedimentos após acidente com material biológico. Além de aspectos relacionados à população do estudo como: faixa etária, sexo e grau de instrução ou, no caso dos discentes, semestre em que se encontra na universidade.

Nenhuma identificação foi feita nos questionários, confirmando o anonimato no preenchimento dos mesmos. Os dados coletados foram analisados pelo software SPSS (Statistical Package for Social Sciences, IBM Inc., USA) versão 22.0. 
Foram realizadas análises de estatística descritiva para obtenção de frequências absoluta e relativa de respostas. A associação entre variáveis qualitativas foi verificada pelo teste Qui-Quadrado $\left(\mathrm{X}^{2}\right)$. Foi adotado o nível de significância de 5\% $(p<0,05)$.

\section{RESULTADOS}

No total, foram avaliados questionários respondidos por 19 docentes, 17 técnicos, 156 discentes e 7 empregados da limpeza de um total de 29 docentes, 17 técnicos, 218 discentes e 10 empregados da limpeza. Os docentes não participantes não estavam em exercício no Departamento de Odontologia durante o período da pesquisa. Os discentes que não participaram da pesquisa não estavam incluídos no critério de inclusão de idade (acima de 18 anos) ou constavam nas listas da matrícula, mas não estavam frequentando as aulas. Os 3 empregados da limpeza que não participaram da pesquisa não eram envolvidos na limpeza das clínicas ou laboratórios do Departamento.

\section{Resultados dos docentes}

A Tabela 1 mostra todos os dados coletados dos docentes. Dos docentes analisados, 52,6\% ensinam biossegurança formalmente. Somente um docente não sabia ou não respondeu se era vacinado contra a hepatite B. $57,9 \%$ dos docentes já sofreram acidente com material perfurocortante. $15,8 \%$ relataram que já descartaram material perfurocortante em sacos plásticos. $84,2 \%$ abordam o tema biossegurança em sala de aula. 31,6\% acreditam que os alunos não são conscientes das normas de biossegurança e $100 \%$ dos docentes entrevistados acreditam que devem passar por uma reciclagem sobre biossegurança.

Também foram apresentados três casos no contexto biossegurança. $O$ primeiro sugeriu um possível acidente com uma agulha contaminada em um funcionário da limpeza e questionou se os docentes concordam que o procedimento de procurar a direção após o ocorrido é certo. 73,7\% dos discentes disseram que sim. No segundo caso, foi questionado se os docentes consideram que perguntar a um paciente se ele já fez o exame de HIV/AIDS antes de iniciar o atendimento deve ser considerada uma medida de prevenção em consultório odontológico. 63,2\% responderam que sim e 36,8\% responderam que não. No terceiro caso, foi questionado se os docentes concordam com a recusa de um aluno em atender um paciente que relata ser portador do HIV/AIDS e estar com problemas de sangramento decorrentes da medicação. 63,2\% não concordam com essa atitude.

\section{Resultados dos técnicos}

A Tabela 2 mostra todos os dados coletados dos técnicos. Dos técnicos analisados, 64,7\% não receberam treinamento prévio para desempenhar sua função com segurança. 88,2\% não recebem treinamento periódico para esclarecer dúvidas sobre prevenção de acidentes de trabalho. $41,2 \%$ fazem uso do EPI. $94,1 \%$ acreditam que roupas e jalecos podem ser veículos para patógenos humanos. 75,6\% são vacinados contra Hepatite B. 
Tabela 1. Respostas dos docentes sobre biossegurança.

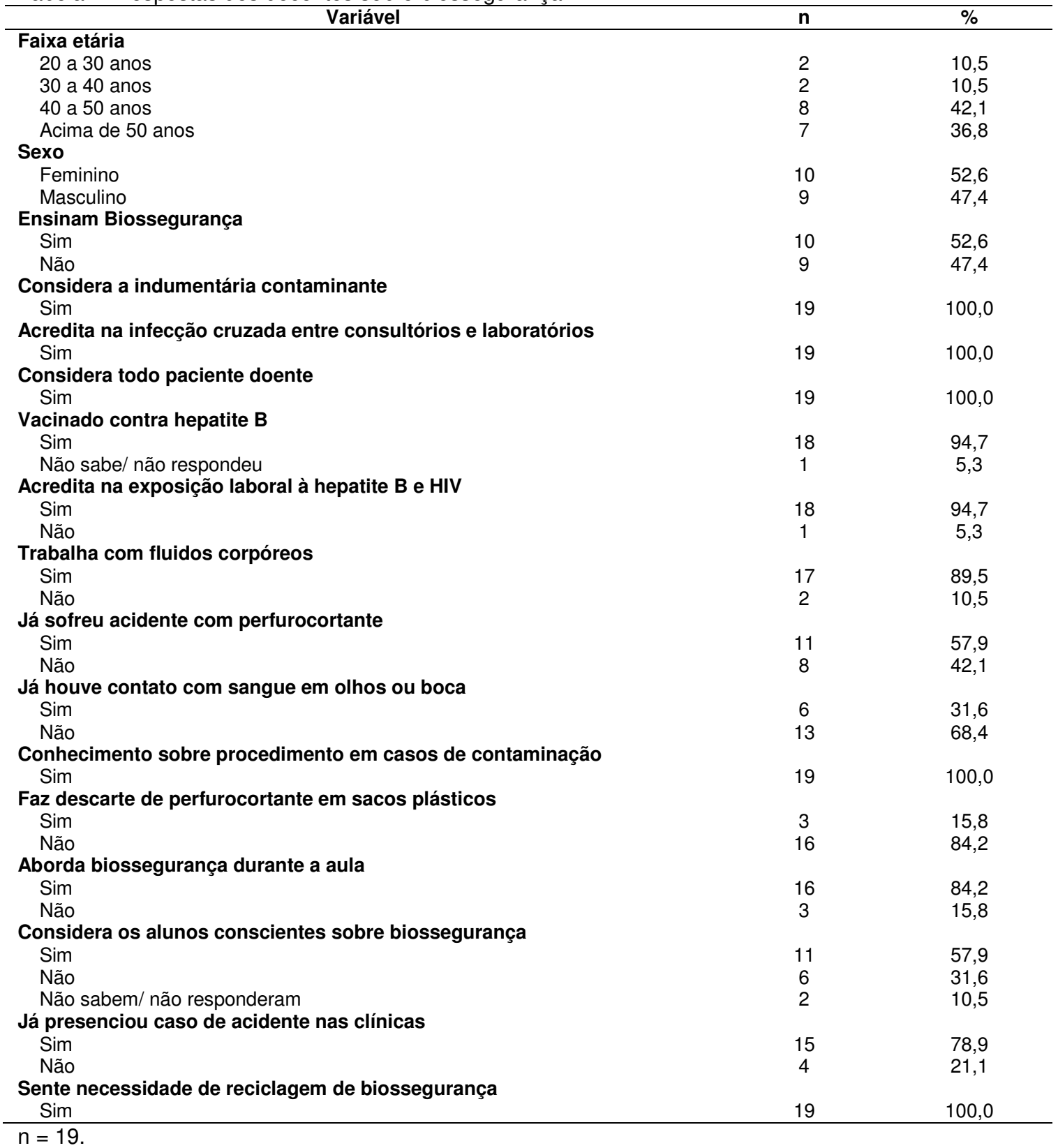

A Tabela 2 também demonstra que $94,1 \%$ dos técnicos não fizeram o teste para confirmar a imunização da vacina contra Hepatite B. 76,5\% acreditam na exposição ao vírus da Hepatite B ou HIV durante o trabalho. $58,8 \%$ trabalham com material contaminado de sangue ou saliva. $70,6 \%$ já sofreram acidente com material perfurocortante. $23,5 \%$ já tiveram contato com sangue ou saliva em olhos ou boca. $58,8 \%$ têm conhecimento sobre os procedimentos a serem tomados em caso de exposição a sangue. $41,2 \%$ fazem descarte de material perfurocortante em sacos plásticos. $76,5 \%$ fazem a identificação de sacos ou caixas com material contaminado. $100 \%$ gostariam de receber mais informações sobre como evitar contaminação ocupacional. 88,2\% já fizeram uso da metodologia de mapa de risco para monitorar ambiente laboratorial ou outro. $41,2 \%$ já presenciaram acidentes com risco no laboratório durante aulas práticas. $70,6 \%$ 
consideram que os alunos não tem conhecimento sobre biossegurança.

Tabela 2. Respostas dos técnicos sobre biossegurança.

\begin{tabular}{|c|c|c|}
\hline $\begin{array}{ll}\text { Variável } \\
\end{array}$ & $\mathbf{n}$ & $\%$ \\
\hline \multicolumn{3}{|l|}{ Faixa etária } \\
\hline 30 a 40 anos & 8 & 47,1 \\
\hline Acima de 40 anos & 9 & 52,9 \\
\hline \multicolumn{3}{|l|}{ Sexo } \\
\hline Feminino & 10 & 58,8 \\
\hline Masculino & 7 & 41,2 \\
\hline \multicolumn{3}{|l|}{ Nível de instrução } \\
\hline Ensino fundamental & 1 & 5,9 \\
\hline Ensino médio completo & 3 & 17,6 \\
\hline Superior incompleto & 4 & 23,5 \\
\hline Superior completo & 1 & 5,9 \\
\hline Pós-graduação incompleta & 4 & 23,5 \\
\hline Pós-graduação completa & 3 & 17,6 \\
\hline \multicolumn{3}{|l|}{ Recebeu treinamento prévio para o cargo } \\
\hline Sim & 6 & 35,3 \\
\hline Não & 11 & 64,7 \\
\hline \multicolumn{3}{|c|}{ Recebe treinamento periódico para prevenção de acidentes } \\
\hline Sim & 2 & 11,8 \\
\hline Não & 15 & 88,2 \\
\hline \multicolumn{3}{|l|}{ Faz uso de EPI } \\
\hline Sim & 7 & 41,2 \\
\hline Não & 3 & 17,6 \\
\hline Às vezes & 5 & 29,4 \\
\hline Não respondeu & 2 & 11,8 \\
\hline \multicolumn{3}{|l|}{ Acredita que roupas e jalecos são contaminantes } \\
\hline Sim & 16 & 94,1 \\
\hline Não & 1 & 5,9 \\
\hline \multicolumn{3}{|l|}{ Vacinado contra hepatite B } \\
\hline Sim & 13 & 76,5 \\
\hline Não sabe & 4 & 23,5 \\
\hline \multicolumn{3}{|l|}{ Já fez o teste para confirmar imunização } \\
\hline Não & 16 & 94,1 \\
\hline Não sabe/ não respondeu & 1 & 5,9 \\
\hline \multicolumn{3}{|l|}{ Acredita na exposicão laboral à hepatite B e HIV } \\
\hline Sim & 13 & 76,5 \\
\hline Não & 4 & 23,5 \\
\hline \multicolumn{3}{|c|}{ Trabalha com objetos contaminados de sangue ou saliva } \\
\hline Sim & 10 & 58,8 \\
\hline Não sabe/ não respondeu & 7 & 41,2 \\
\hline \multicolumn{3}{|l|}{ Já sofreu acidente com perfurocortante } \\
\hline Sim & 12 & 70,6 \\
\hline Não & 5 & 29,4 \\
\hline \multicolumn{3}{|c|}{ Já teve contato com sangue ou saliva em olhos ou boca } \\
\hline Sim & 4 & 23,5 \\
\hline Não & 13 & 76,5 \\
\hline Tem conhecimento sobre procedimentos em ca & & \\
\hline Sim & 10 & 58,8 \\
\hline Não & 7 & 41,2 \\
\hline Faz descarte de perfurocortante em sacos plást & & \\
\hline Sim & 7 & 41,2 \\
\hline Não & 9 & 52,9 \\
\hline Não sabe/não respondeu & 1 & 5,9 \\
\hline Faz identificação de sacos e plásticos com mate & & \\
\hline Sim & 13 & 76,5 \\
\hline Não & 4 & 23,5 \\
\hline Gostaria de receber informação para evitar acid & & \\
\hline Sim & 17 & 100,0 \\
\hline Já usou mapa de risco & & \\
\hline Sim & 15 & 88,2 \\
\hline Não & 2 & 11,8 \\
\hline Presenciou acidente em laboratório durante aul & & \\
\hline Sim & 7 & 41,2 \\
\hline Não & 7 & 41,2 \\
\hline Não sabe/não respondeu & 3 & 17,6 \\
\hline Acha que os alunos tem conhecimento de bioss & & \\
\hline $\operatorname{Sim}$ & 3 & 17,6 \\
\hline Não & 12 & 70,6 \\
\hline Não sabe/não respondeu & 2 & 11,8 \\
\hline
\end{tabular}




\section{Resultados dos discentes}

A Tabela 3 mostra todos os dados coletados dos discentes. Dos discentes analisados, $11,5 \%$ consideram que não conhecem ou não fazem uso das medidas de biossegurança. 17,9\% assumiram que não fazem o uso completo do EPI. 3,2\% relataram que fazem uso do celular ou do bebedouro com as luvas e $10,9 \%$ que fazem uso do celular ou do bebedouro com as luvas às vezes. $23,7 \%$ não são vacinados contra a hepatite $B$ e do restante que foi vacinado, $91,0 \%$ não fizeram o teste de imunidade para hepatite B. $25,6 \%$ já sofreram acidente com perfurocortantes. $12,8 \%$ assumem que descartam perfurocortantes em sacos plásticos. 83,3\% interromperiam o atendimento diante de um acidente com material perfurocortante potencialmente infectado. $36,5 \%$ acham que o reencape da agulha com as duas mãos para protegê-la da contaminação é correto. $55,8 \%$ relatam que não saberiam se portar diante um acidente durante $\mathrm{o}$ atendimento. $80,1 \%$ concordam que as medidas de biossegurança devem ser as mesmas para qualquer paciente. $48,7 \%$ julgam que a as informações que recebem sobre biossegurança não são suficientes para uma prática clínica segura.

Nos questionários, apresentaram-se dois casos no contexto biossegurança. $O$ primeiro caso questiona se perguntar ao paciente se ele já fez o exame de HIV/AIDS antes do atendimento deve ser adotado como medida de prevenção. $64,7 \%$ dos discentes acreditam que sim.

No segundo caso, questiona-se se os discentes concordam com a atitude de recusar atendimento que necessita de procedimentos invasivos, nos quais 0 contato com sangue ocorreria, no caso do paciente informar ser portador do HIV/AIDS. $83,3 \%$ não concordam.

\section{Resultados dos empregados da limpeza}

A Tabela 4 mostra todos os dados coletados dos funcionários da limpeza. Dos funcionários da limpeza analisados, 42,9\% não sabem o que é biossegurança. 100\% não recebem treinamento periódico sobre biossegurança. $100 \%$ não receberam capacitação para realizar seu trabalho. $100 \%$ não usam luvas descartáveis. $28,6 \%$ consideram que a vestimenta não é adequada para realizar o trabalho. $71,4 \%$ não sabem se foram vacinados contra a Hepatite B. $100 \%$ acreditam na possibilidade de ser contaminado durante 0 trabalho. $85,7 \%$ acreditam que o uniforme pode ser veículo para transmissão de doenças. $57,1 \%$ já sofreram acidente com material perfurocortante. $71,4 \%$ possuem conhecimento sobre os procedimentos a serem tomados após acidente com material contaminado. $85,7 \%$ já encontraram materiais perfurocortantes descartados em sacos plásticos durante a remoção do lixo. $100 \%$ gostariam de receber mais informações sobre biossegurança.

Nos questionários dos funcionários, apresentaram-se dois casos no contexto biossegurança. No primeiro caso, a funcionária sofre um corte na mão com agulha de seringa utilizada, continua a limpeza e só depois, procura a direção para contar o ocorrido. 
Tabela 3. Respostas dos discentes sobre biossegurança.

\begin{tabular}{|c|c|c|}
\hline $\begin{array}{ll} & \text { Variável }\end{array}$ & $\mathbf{n}$ & $\%$ \\
\hline \multicolumn{3}{|l|}{ Faixa etária } \\
\hline 18 a 20 anos & 48 & 30,8 \\
\hline 20 a 30 anos & 106 & 67,9 \\
\hline Acima de 30 anos & 2 & 1,3 \\
\hline \multicolumn{3}{|l|}{ Sexo } \\
\hline Feminino & 119 & 76,3 \\
\hline Masculino & 37 & 23,7 \\
\hline \multicolumn{3}{|c|}{ Julga que tem conhecimento e faz uso de medidas de biossegurança } \\
\hline Sim & 137 & 87,8 \\
\hline Não & 18 & 11,5 \\
\hline Não sabe/ não respondeu & 1 & 0,6 \\
\hline \multicolumn{3}{|l|}{ Faz uso de EPI completo } \\
\hline Sim & 128 & 82,1 \\
\hline Não & 28 & 17,9 \\
\hline \multicolumn{3}{|l|}{ Faz uso de celular e/ou bebedouro com luvas } \\
\hline Sim & 5 & 3,2 \\
\hline Não & 132 & 84,6 \\
\hline Às vezes & 17 & 10,9 \\
\hline Não sabe/ não respondeu & 2 & 1,3 \\
\hline \multicolumn{3}{|l|}{ Vacinado contra hepatite B } \\
\hline Sim & 119 & 76,3 \\
\hline Não & 37 & 23,7 \\
\hline \multicolumn{3}{|l|}{ Realizou o teste para confirmar vacinação } \\
\hline Sim & 13 & 8,4 \\
\hline Não & 142 & 91,0 \\
\hline Não sabe/ não respondeu & 1 & 0,6 \\
\hline \multicolumn{3}{|c|}{ Acredita na possível exposição durante o curso à hepatite B e HIV } \\
\hline $\operatorname{Sim}$ & 137 & 87,8 \\
\hline Não & 17 & 10,9 \\
\hline Não sabe/ não respondeu & 2 & 1,3 \\
\hline \multicolumn{3}{|l|}{ Trabalha com sangue } \\
\hline Sim & 62 & 39,7 \\
\hline Não & 92 & 59,0 \\
\hline Não sabe/ não respondeu & 2 & 1,3 \\
\hline \multicolumn{3}{|l|}{ Já teve acidente com perfurocortante } \\
\hline Sim & 40 & 25,6 \\
\hline Não & 116 & 74,4 \\
\hline \multicolumn{3}{|l|}{ Já houve contato com sangue em olhos ou boca } \\
\hline Sim & 34 & 21,8 \\
\hline Não & 119 & 76,3 \\
\hline Não sabe/ não respondeu & 3 & 1,9 \\
\hline \multicolumn{3}{|c|}{ Faz descarte de perfurocortante em sacos plásticos } \\
\hline Sim & 20 & 12,8 \\
\hline Não & 134 & 85,9 \\
\hline Não sabe/ não respondeu & 2 & 1,6 \\
\hline \multicolumn{3}{|c|}{$\begin{array}{l}\text { Interromper atendimento diante acidente com objeto perfurocortante } \\
\text { contaminado }\end{array}$} \\
\hline Sim & 130 & 83,3 \\
\hline Não & 24 & 15,4 \\
\hline Não sabe/não respondeu & 2 & 1,6 \\
\hline \multicolumn{3}{|c|}{ Considera reencape de agulha com as duas mãos correto } \\
\hline Sim & 57 & 36,5 \\
\hline Não & 98 & 62,8 \\
\hline Não sabe/não respondeu & 1 & 0,6 \\
\hline \multicolumn{3}{|c|}{ Concorda com medidas universais de biossegurança } \\
\hline Sim & 125 & 80,1 \\
\hline Não & 28 & 18,0 \\
\hline Não sabe/não respondeu & 3 & 1,9 \\
\hline Conhece as medidas profiláticas em caso de a & & \\
\hline Sim & 66 & 42,3 \\
\hline Não & 87 & 55,8 \\
\hline Não sabem/ não responderam & 3 & 1,9 \\
\hline Acredita que as informações sobre biossegura & & \\
\hline Sim & 77 & 49,4 \\
\hline Não & 76 & 48,7 \\
\hline Não sabe/não respondeu & 3 & 1,9 \\
\hline
\end{tabular}

$\mathrm{n}=156$.

$\mathrm{Na}$ primeira pergunta foi correto procurar a direção da clínica após a questionado se os funcionários consideram funcionária sofrer 0 acidente. $71,4 \%$ 
concordam que a funcionária agiu corretamente ao procurar a direção. 85,7\% acham que a funcionária deveria ter procurado ajuda logo após o ocorrido. 100\% não acreditam que possam perder o emprego por procurar a direção devido ao acidente ocorrido. $71,4 \%$ saberiam como se portar diante a um acidente como no caso apresentado.
No segundo caso, um paciente vomita no chão durante 0 atendimento clínico e uma funcionária fez a limpeza sem o uso de luvas. Neste caso, foi questionado se os funcionários acreditam que a atitude na limpeza foi correta. $100 \%$ responderam que não.

Tabela 4. Respostas dos empregados da limpeza sobre biossegurança.

\begin{tabular}{|c|c|c|}
\hline Variável & $\mathbf{n}$ & $\%$ \\
\hline \multicolumn{3}{|l|}{ Faixa etária } \\
\hline 20 a 30 anos & 1 & 14,3 \\
\hline 30 a 40 anos & 4 & 57,1 \\
\hline Acima de 40 anos & 2 & 28,6 \\
\hline \multicolumn{3}{|l|}{ Sexo } \\
\hline Feminino & 7 & 100,0 \\
\hline Masculino & 0 & 0,0 \\
\hline \multicolumn{3}{|l|}{ Nível de instrução } \\
\hline Até $4^{\mathrm{a}}$ série & 1 & 14,3 \\
\hline Da $4^{\underline{a}}$ até $8^{\underline{a}}$ série & 1 & 14,3 \\
\hline Ensino médio & 1 & 14,3 \\
\hline Superior incompleto & 4 & 57,1 \\
\hline \multicolumn{3}{|l|}{ Sabe o que é biossegurança } \\
\hline Sim & 3 & 42,9 \\
\hline Não & 3 & 42,9 \\
\hline Não sabe/ não respondeu & 1 & 14,3 \\
\hline \multicolumn{3}{|c|}{ Recebe ou já recebeu treinamento periódico sobre biossegurança } \\
\hline $\operatorname{Sim}$ & 0 & 0,0 \\
\hline Não & 7 & 100,0 \\
\hline \multicolumn{3}{|l|}{ Este treinamento capacitou para trabalho } \\
\hline Sim & 0 & 0,0 \\
\hline Não & 7 & 100,0 \\
\hline \multicolumn{3}{|l|}{ Usa luvas descartáveis } \\
\hline Sim & 0 & 0,0 \\
\hline Não & 7 & 100,0 \\
\hline \multicolumn{3}{|l|}{ Acha que possui vestimenta adequada } \\
\hline Sim & 5 & 71,4 \\
\hline Não & 2 & 28,6 \\
\hline \multicolumn{3}{|l|}{ Vacinado contra hepatite B } \\
\hline Sim & 2 & 28,6 \\
\hline Não sabe & 5 & 71,4 \\
\hline \multicolumn{3}{|c|}{ Acredita na possibilidade de contaminar durante trabalho } \\
\hline Sim & 7 & 100,0 \\
\hline Não & 0 & 0,0 \\
\hline \multicolumn{3}{|l|}{ Acredita que o uniforme pode ser contaminante } \\
\hline Sim & 6 & 85,7 \\
\hline Não sabe/ não respondeu & 1 & 14,3 \\
\hline \multicolumn{3}{|l|}{ Já sofreu acidente com perfurocortante } \\
\hline Sim & 4 & 57,1 \\
\hline Não & 3 & 42,9 \\
\hline \multicolumn{3}{|c|}{$\begin{array}{l}\text { Tem conhecimento sobre procedimentos em caso de acidentes com exposição à } \\
\text { sangue }\end{array}$} \\
\hline Sim & 5 & 71,4 \\
\hline Não & 2 & 28,6 \\
\hline \multicolumn{3}{|c|}{ Já encontrou material perfurocortante em sacos plásticos } \\
\hline Sim & 6 & 85,7 \\
\hline Não & 1 & 14,3 \\
\hline \multicolumn{3}{|c|}{ Gostaria de receber informação sobre biossegurança } \\
\hline Sim & 7 & 100,0 \\
\hline Não & 0 & 0,0 \\
\hline
\end{tabular}

$\mathrm{n}=7$. 
Associação entre os resultados de cada grupo

$\mathrm{Na}$ Tabela 5, apresentam-se os resultados da comparação da prevalência do conhecimento e uso de medidas de biossegurança, ocorrência de acidentes com material perfurocortante e vacinação contra Hepatite B entre os grupos de docentes, discentes, técnicos e funcionários da limpeza. Nesta avaliação, observa-se que, comparativamente, os funcionários da limpeza são os que menos possuem o conhecimento de biossegurança, seguidos dos técnicos. Com relação aos acidentes com material perfurocortante, docentes, discentes e funcionários da limpeza são acometidos na proporção de 57,9\%, 25,6\%, $57,1 \%$, respectivamente e os técnicos são os mais acometidos, com $70,6 \%$. Em relação à vacinação contra Hepatite $\mathrm{B}$, os funcionários da limpeza são os que menos têm certeza da vacinação e os docentes são os mais vacinados.

$\mathrm{Na}$ Tabela 6, foi realizada uma associação entre julgamento do conhecimento e do uso de medidas de biossegurança pelos alunos e julgamento se as informações sobre biossegurança ensinadas durante o curso são suficientes para uma prática clínica segura. Dos alunos que julgam que as informações sobre biossegurança durante o curso não são suficientes, 90,7\% relataram que conhecem e fazem uso das medidas de biossegurança. Dos alunos que julgam que as informações não são suficientes, 85,7\% relataram que conhecem e fazem uso das medidas de biossegurança.

Tabela 5. Comparação da prevalência do conhecimento e uso de medidas de biossegurança, ocorrência de acidentes com material perfurocortante e vacinação contra Hepatite B entre os grupos analisados nos questionários.

\begin{tabular}{|c|c|c|c|c|c|c|c|c|c|}
\hline $\begin{array}{l}\text { Conhecimento e uso de } \\
\text { medidas de } \\
\text { biossegurança }\end{array}$ & \multicolumn{2}{|c|}{$\begin{array}{c}\text { Docente } \\
\text { n (\%) }\end{array}$} & \multicolumn{2}{|c|}{$\begin{array}{c}\text { Discente } \\
\mathrm{n}(\%)\end{array}$} & \multicolumn{2}{|c|}{$\begin{array}{c}\text { Técnico } \\
\text { n (\%) }\end{array}$} & \multicolumn{2}{|c|}{$\begin{array}{c}\text { Limpeza } \\
\text { n (\%) }\end{array}$} & $\mathbf{P}$ \\
\hline Sim & 19 & 100,0 & 137 & 87,8 & 10 & 58,8 & 3 & 42,9 & \multirow{3}{*}{0,001} \\
\hline Não & 0 & 0,0 & 18 & 11,5 & 7 & 41,2 & 3 & 42,9 & \\
\hline $\begin{array}{l}\text { Não sabe/ não } \\
\text { respondeu }\end{array}$ & 0 & 0,0 & 1 & 0,6 & 0 & 0,0 & 1 & 14,3 & \\
\hline \multicolumn{10}{|c|}{ Acidente perfurocortante } \\
\hline Sim & 11 & 57,9 & 40 & 25,6 & 12 & 70,6 & 4 & 57,1 & \multirow{2}{*}{$<0,001$} \\
\hline Não & 8 & 42,1 & 116 & 74,4 & 5 & 29,4 & 3 & 42,9 & \\
\hline \multicolumn{10}{|c|}{$\begin{array}{l}\text { Vacinado contra hepatite } \\
\text { B }\end{array}$} \\
\hline Sim & 18 & 94,7 & 119 & 76,3 & 13 & 76,5 & 2 & 28,6 & \multirow{3}{*}{$<0.001$} \\
\hline Não & 0 & 0,0 & 37 & 23,7 & 0 & 0,0 & 0 & 0.0 & \\
\hline $\begin{array}{l}\text { Não sabe/ não } \\
\text { respondeu }\end{array}$ & 1 & 5,3 & 0 & 0,0 & 4 & 23,5 & 5 & 71,4 & \\
\hline
\end{tabular}

Tabela 6. Associação entre julgamento do conhecimento/uso de medidas e julgamento se as informações sobre biossegurança, por discentes, se são suficientes para uma prática clínica segura.

\begin{tabular}{lccc} 
& Conhecimento e uso de medidas de biossegurança & Não & $\mathrm{p}$ \\
& $\operatorname{Sim}$ & $\mathrm{n}(\%)$ & \\
Informações sobre biossegurança são & $\mathrm{n}(\%)$ & & \\
suficientes durante o curso & & $11(14,3)$ & 0,345 \\
Sim & $66(85,7)$ & $7(9,3)$ & \\
Não & $68(90,7)$ & & \\
\hline
\end{tabular}


$\mathrm{Na}$ Tabela 7, dos alunos que relatam que têm conhecimento de biossegurança e fazem uso delas, 10,9\% não fazem uso completo do EPI e dos alunos que relatam que não têm conhecimento e não fazem uso das medidas de biossegurança, 66,7\% não fazem uso completo do EPI.

$\mathrm{Na}$ Tabela 8 foi realizada uma comparação entre os períodos que os alunos se encontram no curso com a percepção se os conhecimentos recebidos durante o curso são suficientes para uma prática clínica segura. Do primeiro ao quinto período, $61,8 \%$ acreditam que as informações recebidas são suficientes. Do sexto ao nono período, 38,2\% acreditam que as informações recebidas são suficientes.

Tabela 7. Associação entre atitude e julgamento de informações sobre biossegurança realizados pelos discentes.

\begin{tabular}{|c|c|c|c|}
\hline & \multicolumn{3}{|c|}{$\begin{array}{c}\text { Consideram que tem conhecimento e fazem uso de } \\
\text { medidas de biossegurança }\end{array}$} \\
\hline & $\begin{array}{c}\text { Sim } \\
\mathrm{n}(\%)\end{array}$ & $\begin{array}{c}\text { Não } \\
\text { n (\%) }\end{array}$ & $\mathrm{p}$ \\
\hline \multicolumn{4}{|l|}{ Uso de EPI's } \\
\hline $\begin{array}{l}\text { Sim } \\
\text { Não }\end{array}$ & $\begin{array}{l}122(89,1) \\
15(10,9)\end{array}$ & $\begin{array}{c}6(33,3) \\
12(66,7)\end{array}$ & $<0,001$ \\
\hline \multicolumn{4}{|c|}{ Uso de celular e/ou bebedouro com luvas } \\
\hline Sim & $5(3,7)$ & $0(0,0)$ & \multirow{3}{*}{0,524} \\
\hline Não & $115(85,2)$ & $17(94,4)$ & \\
\hline Às vezes & $15(11,1)$ & $1(5,6)$ & \\
\hline
\end{tabular}

Tabela 8. Associação entre o período que o discente se encontra no curso com o julgamento se as informações sobre biossegurança ensinadas durante o curso são suficientes

\begin{tabular}{cccc}
\hline & \multicolumn{3}{c}{ Informações sobre biossegurança suficientes } \\
\hline & $\operatorname{Sim}$ & Não & \\
Período & $n(\%)$ & $n(\%)$ & \\
$1^{\circ}$ ao $5^{\circ}$ & $47(61,8)$ & $48(63,2)$ & 0,867 \\
$6^{\circ}$ ao $9^{\circ}$ & $29(38,2)$ & $28(36,8)$ & \\
\hline
\end{tabular}

\section{DISCUSSÃO}

A Universidade Federal dos Vales do Jequitinhonha e Mucuri (UFVJM), uma importante instituição no Vale do Jequitinhonha e para a cidade de Diamantina, a qual aloja dois Campi dessa instituição, passa por um crescimento acelerado em suas atividades e estrutura. Com a ampliação das atividades laboratoriais e de prestação de serviço na área de saúde aumentam, consequentemente, todos os riscos a elas relacionados. Portanto, é necessário pensar em estratégias e meios que incentivem permanentemente 0 respeito às práticas de Biossegurança.
A partir dos resultados obtidos, observa-se que, apesar de $84,2 \%$ dos docentes relatarem que abordam o tema biossegurança e 52,6\% ensinarem este conteúdo formalmente em sala de aula, $31,6 \%$ dos docentes consideram que os alunos não são conscientes sobre biossegurança. No trabalho elaborado por Pereira et al. $(2010)^{3}$, evidencia-se a importância de uma maior articulação entre - saber científico, das normas de biossegurança e o saber da prática. No mesmo artigo, enfatiza-se a demanda de uma reestruturação pedagógica para a formação de profissionais competentes. Através desse resultado, pode-se observar 
que o corpo docente está ciente da realidade presente na rotina prática dos seus alunos. É importante, portanto, a apresentação destes dados para sugerir outra proposta pedagógica que não só enfatize as regras e normas de biossegurança como apresente um enfoque mais participativo para ultrapassar a difusão do conhecimento. Destaca-se, ainda, que, entre os docentes, $100 \%$ sentem a necessidade de passar por reciclagem sobre o tema biossegurança. Em um estudo realizado por Diaz-Tamayo e Vivas $(2016)^{19}$, que avaliaram 78 docentes sobre 0 conhecimento e práticas de biossegurança, somente um terço conhecia os riscos biológicos e práticas e, uma porcentagem ainda menor, aplicava as práticas na rotina clínica. Portanto, há a necessidade também de capacitar o corpo docente para transmitir o conhecimento de biossegurança de forma correta e praticá-lo a fim de reduzir o espaço entre o conhecimento teórico e prático, dando exemplo para os estudantes.

Ainda no contexto da construção do conhecimento em biossegurança, 42,9\% dos funcionários da limpeza relataram não saber o que é biossegurança, 100\% não receberam nenhuma capacitação para exercerem suas atividades e $100 \%$ gostariam de receber mais informações sobre 0 assunto. Interessante notar o contrassenso que, muito embora os funcionários relatem que não recebem capacitação, sentem-se preparados para enfrentar situações de acidente com exposição a sangue. Seria necessário então, investigar qual a fonte de informação que os mesmos estão utilizando. É preocupante o resultado encontrado dentre os funcionários da limpeza, visto que a universidade possui sete graduações da área da saúde: Odontologia, medicina, farmácia, nutrição, fisioterapia, enfermagem, educação física e em nenhum momento foi realizada a capacitação necessária. Apesar da equipe de limpeza ser um serviço terceirizado, a universidade deveria, como uma instituição educadora e, reconhecendo o ambiente insalubre de trabalho dos funcionários, cobrar essa capacitação da empresa contratada. Além disso, pode-se propor que essa capacitação seja realizada dentro do ambiente universitário através de projetos de ensino e extensão.

Esta capacitação também se mostra necessária entre os técnicos do Departamento de Odontologia, onde 64,7\% relataram que não receberam treinamento prévio para exercerem suas funções e somente $11,8 \%$ recebem treinamento periódico para prevenção de acidentes, evidenciando a defasagem na educação da biossegurança.

Analisando os resultados dos discentes, 48,7\% dos alunos consideram que o ensino realizado durante o curso não é suficiente para uma prática clínica segura. Este resultado difere do estudo realizado por Lages et al. $(2015)^{20}$, que avaliaram o conhecimento e práticas de biossegurança em duas instituições de ensino (IES), uma particular e outra pública no estado de Alagoas, no qual cerca de $90 \%$ dos alunos se sentiam muito satisfeitos ou satisfeitos com o conhecimento adquirido na instituição particular e 64\% na instituição pública. Observou-se também que 17,9\% não fazem uso do EPI completo e 10,9\% assumiram que fazem uso do celular ou do bebedouro 
com luvas às vezes Este resultado também se difere do estudo de Lages et al. $(2015)^{20}$, no qual mais de $90 \%$ dos alunos da instituição particular relaram usar o EPI completo sempre. Os alunos da instituição pública também tiveram resultados semelhantes, somente diferente no que se refere ao uso dos óculos de proteção, no qual $67 \%$ relataram usar sempre e $30 \%$ às vezes.

$\mathrm{Na}$ Tabela 6, foi feita a associação entre os julgamentos dos alunos acerca de seu próprio conhecimento e do uso de medidas de biossegurança e julgamento se as informações sobre biossegurança dadas durante o curso são suficientes para uma prática clínica segura. A associação não foi significativa, ou seja, os julgamentos não têm correlação. Esta observação pode evidenciar a dissociação entre 0 saber prático e o saber teórico dentro do contexto biossegurança. Essa diferença já foi relatada no estudo realizado por Pereira et al. $(2010)^{3}$.

$\mathrm{Na}$ Tabela 7, foi realizada uma associação entre atitude e o julgamento dos alunos acerca de seu próprio conhecimento e do uso de medidas de biossegurança. Para analisar a atitude, os discentes foram questionados sobre a prática de duas medidas, o uso completo do EPI e o uso do celular e/ou bebedouros calçando as luvas. Em relação à associação com o uso de EPI, houve significância $(p>0,001)$. Ou seja, os que acreditam ter 0 conhecimento de biossegurança e praticá-lo em sua rotina clínica, fazem em maior proporção o uso do EPI completo e os que não acreditam, fazem o uso do EPI completo em menor proporção. Já para análise da associação com o uso de celulares ou bebedouro com as luvas, não foi significativo. Portanto, não há essa correlação e a atitude do uso de celular e bebedouros com as luvas pode ser um indicativo da falta de esforço pessoal para o cumprimento das normas de biossegurança.

$\mathrm{Na}$ Tabela 8, foi investigada a associação entre o período que o aluno se encontra no curso com o julgamento se as informações sobre biossegurança ensinadas durante o curso são suficientes. $\mathrm{Na}$ análise, não foi significativo. Portanto, não há relação entre o nível no qual o aluno se encontra e o seu julgamento sobre a eficácia do ensino de biossegurança dentro do curso.

A não adesão das medidas preventivas é um dos agravantes que contribuem para a ocorrência de acidentes. Dos discentes analisados, $55,8 \%$ não saberiam se portar diante a um acidente com material contaminado, apesar de $25,6 \%$ relatarem que já sofreram algum acidente com material perfurocortante contaminado com material biológico. No estudo de Lages et al. $(2015)^{20}, 96 \%$ dos alunos da IES particular e $60 \%$ dos alunos da IES pública tinham conhecimento do protocolo frente a um acidente com material biológico. No estudo realizado por Gir et al. (2008) ${ }^{9}$, dos acidentes registrados entre graduandos da área da saúde, a maioria ocorreu com estudantes da Odontologia. Estes resultados evidenciam a necessidade de repensar a maneira como o assunto é abordado e capacitar os alunos diante das situações de risco de contaminação. Dentre os grupos analisados de docentes, técnicos e funcionários da limpeza, a maioria já 
sofreu acidente com material perfurocortante $(57,9 \%, 70,6 \%$ e $57,1 \%$ respectivamente). $41,2 \%$ dos técnicos e $78,9 \%$ dos docentes analisados já presenciaram acidentes em laboratórios e clínicas.

A literatura aponta a via percutânea como a mais comum na exposição ocupacional entre dentistas, graduandos de Odontologia e funcionários da limpeza ${ }^{9,15,21}$ muito embora a via de contaminação não tenha sido pesquisada no presente estudo.

Em um estudo realizado por Barros et al. $(2010)^{22}$, com trabalhadores da coleta de resíduos do serviço de saúde, identificou-se que apesar dos funcionários adotarem os equipamentos de proteção, a elevada exposição biológica se faz pela disposição interna inadequada das fontes geradoras. Na análise dos funcionários da limpeza, 85,7\% já encontraram material perfurocortante descartados de forma incorreta em sacos de lixo. Em uma revisão feita por Oliveira et al. $(2015)^{21}$, sobre acidentes com perfurocortantes entre trabalhadores da saúde, os profissionais do serviço de higienização se destacam no acometimento por acidentes e as ocorrências se devem, principalmente, pelo descarte incorreto de material. Quando questionados sobre o descarte de material perfurocortante, $41,2 \%$ dos técnicos, $12,8 \%$ dos discentes e $15,58 \%$ dos docentes relataram que descartam material perfurocortante em sacos plásticos. Essa alta porcentagem pode ser devido a uma má interpretação da pergunta realizada, uma vez que alguns recipientes para descarte de perfurocortantes na UFVJM são de material plástico. Caso contrário, evidencia-se a necessidade de conscientização de todos os grupos analisados sobre o descarte correto de materiais, ressaltando o perigo do descarte incorreto e as possíveis consequências dos acidentes, como a exposição a patógenos.

Ao serem questionados sobre a vacinação contra a Hepatite $B, 94,7 \%$ dos docentes, $76,3 \%$ dos discentes, $76,5 \%$ dos técnicos e, somente, $28,6 \%$ dos funcionários da limpeza responderam que já foram vacinados. No estudo de Lages et al. $(2015)^{20}$, 91\% dos estudantes da (IES) particular já tinham recebido as três doses da vacina e $75 \%$ dos estudantes da IES pública. A vacinação contra o vírus HBV é um desafio para a saúde pública e é muito importante a adesão à vacina dos profissionais da saúde e envolvidos no serviço de saúde, que sofrem um grande risco de exposição ao vírus. No estudo realizado por Gir et al. (2008) ${ }^{9}$, revela-se que, no Brasil, a prevalência de Hepatite $B$ é alta, e há estimativas de pelo menos $15 \%$ da população em geral já ter se exposto ao HBV. Apesar da eficácia da vacina ser alta, além da vacinação, é muito importante a realização do teste anti-HBs para comprovar a resposta vacinal, principalmente pelos indivíduos envolvidos na área da saúde ${ }^{11}$. Apesar dessa importância, 91\% dos discentes analisados não realizaram o teste para verificar a resposta vacinal. No estudo de Lages et al. $(2015)^{20}$, quando questionados sobre o teste de imunidade, $92 \%$ dos alunos da IES particular já tinham feito o exame e somente $20,6 \%$ da IES pública. Com isso, aponta-se a necessidade de uma maior divulgação da necessidade da vacina, da existência do teste anti HBs e 
da importância da sua realização para todos os profissionais ligados ao serviço. Sugerese, ainda, uma cobrança formal da carteira de vacinação pela coordenação do curso de Odontologia, especificamente com relação aos discentes do curso.

A maioria dos envolvidos na pesquisa, dentro de todos os grupos analisados, aponta a consciência de contaminação ocupacional pelos vírus HIV e HBV. Sabe-se que os protocolos de biossegurança têm demonstrado eficácia na prevenção da infecção pelo $\mathrm{HIV}^{23}$. Entretanto, $16,7 \%$ dos discentes respondentes se recusariam a atender um paciente que tenha relatado ser portador do vírus HIV, no caso da necessidade de realizar um procedimento invasivo. Ao responder um questionário sugerindo essa situação, sabe-se que os discentes não estão diante do medo e insegurança de atender um paciente sabidamente portador no vírus HIV, portanto, na prática, essa porcentagem poderia ser ainda maior. $63,2 \%$ dos docentes e $64,7 \%$ dos discentes acreditam que a medida de questionar ao paciente se ele já realizou o exame de HIV antes dos procedimentos deveria ser adotada como medida de prevenção.

É relatada a dificuldade dos pacientes com HIV em conseguir atendimento odontológico quando revelam seu estado de soro positividade ao profissional $^{23}$ e acredita-se que os profissionais ao estarem cientes do paciente ser portador do vírus HIV ou possuir um comportamento de risco para a contaminação, deveria encorajá-los a serem mais cuidadosos no atendimento. Entretanto, evidencia-se a importância da universalidade no atendimento, de considerar que todos os pacientes sejam potencialmente infectados, indiscriminadamente ${ }^{23}$. Levando em consideração essa importância, nos questionários foi perguntado aos discentes e docentes sobre as medidas universais de biossegurança e 100\% dos docentes e $80,1 \%$ dos discentes responderam que consideram todos os pacientes como potencialmente doentes. Assim, faz-se necessário aos docentes alertar os alunos sobre suas obrigações éticas e legais ${ }^{24}$ abordando o tema dos pacientes portadores do vírus HIV e HBV e reforçar a educação para a formação não só de profissionais como de pessoas mais críticas sobre suas atuações na sociedade.

Sangue ou qualquer fluido orgânico contendo sangue visível são materiais biológicos envolvidos na transmissão do HIV (Vírus da Imunodeficiência Humana), portanto pode haver contaminação na prática odontológica $^{12}$. A SIDA se consolidou como uma doença do medo e, pelo medo de acidentes e contaminação, um grande número de profissionais de odontologia teme atender pacientes portadores do HIV. De acordo com Discacciati e Vilaça $(2001)^{23}$ e Discacciati $(1997)^{25}$, havia grande despreparo e desinformação dos profissionais e alunos de odontologia para $\mathrm{o}$ atendimento de pacientes portadores do HIV. Em seus estudos, metade dos profissionais entrevistados concordava que o cirurgiãodentista deveria ter 0 direito de recusar 0 atendimento e a maioria dos entrevistados afirma que deveriam existir clínicas especializadas para atendimento desses 
pacientes. Para Discacciati e Vilaça $(2001)^{23}$, o protocolo de biossegurança para atendimento em consultórios odontológicos, aperfeiçoado ao longo dos anos, tem demonstrado ser eficaz na prevenção da infecção pelo HIV e as instituições de ensino são responsáveis não só pela formação científica dos alunos como também a formação de profissionais da saúde cientes de seus deveres legais e éticos.

É importante também ressaltar sobre a prevenção da hepatite $C$, que se restringe às Precauções Operacionais Padrão. Já a utilização de vacina para hepatite $B$ é recomendada para todos os profissionais de saúde. Após a exposição a material biológico, mesmo para profissionais não imunizados, o uso da vacina, associado ou não a gamaglobulina hiperimune para hepatite B, é uma medida que, comprovadamente, reduz o risco de infecção $^{10}$. De acordo com Canini et al. $(2005)^{15}$, foi identificado que $35,4 \%$ dos trabalhadores de serviço de apoio hospitalar acidentados com material biológico não havia recebido nenhuma dose da vacina contra hepatite B. Com isso, destaca-se a importância de vacinação entre todos os profissionais da saúde e os estudantes de graduação.

As normas de biossegurança servem para reduzir ou evitar a contaminação. Entretanto, apesar de haver regulamentações das normas e produção científica sobre 0 assunto no Brasil, percebe-se outra realidade na prática. De acordo com alguns estudos ${ }^{16,26-29}$, muitos profissionais ainda não observam as normas, tanto proteções individuais como as coletivas. Os profissionais devem adotar uma rotina básica de prevenção para proteção dos pacientes, equipe e ambiente do atendimento contra doenças infectocontagiosas.

Embora os questionários tenham passado por prévia validação semântica $e$ ética $^{18}$, o presente estudo tem como principal limitação a não abrangência nos questionários de todas as dimensões necessárias numa investigação sobre biossegurança. Assim podemos considerar que $o$ assunto foi parcialmente investigado. Mais estudos são necessários para aprofundar o conhecimento de outras vertentes da biossegurança.

Pereira et al. $(2010)^{3}$ analisaram oito trabalhos que são relacionados à prática educacional propriamente dita. Nesta análise, os estudos de Costa e Costa $(2009)^{5}$ e Neves et al. (2006) ${ }^{30}$ propõem que a biossegurança seja desenvolvida de forma mais ampla, a fim de relacionar a prevenção de saúde do homem e do ambiente. Ainda na análise, observa-se que alguns autores propõem que 0 conhecimento em biossegurança seja aplicado em todos os níveis de educação. Muitos trabalhos evidenciam a falta de conhecimento em biossegurança entre trabalhadores da saúde, funcionários da limpeza e acadêmicos dos cursos de saúde. Com isso, há uma intensa necessidade de reformular a metodologia de ensino de biossegurança e a capacitação periódica dos profissionais envolvidos. Neves et al. (2006) ${ }^{30}$ afirmaram que educar significa envolver o indivíduo em sua totalidade, considerando todas as variáveis da história e a cultura de cada um. Assim, em relação à biossegurança, como 
ação educativa que visa à prevenção de acidentes na área de saúde, os autores afirmam que a ela não deve ser reduzida a treino e introjeção de normas, pois a compreensão da biossegurança suscita importantes implicações à saúde do trabalhador, uma vez que considera os agentes como reais sujeitos da aprendizagem. Nesse sentido, é fundamental destacar que, mais do que normatizar, é necessário comprometimento de uma organização/empresa/instituição com a formação do seu pessoal para que os espaços e as práticas atendam aos requisitos necessários para a minimização dos riscos.

Conhecer e compreender os processos de ensino da biossegurança é um importante instrumento estratégicopedagógico, visto a defasagem atual entre o mundo da escola e o do trabalho, no que se refere à biossegurança. Este fato influencia, sobremaneira, a formação profissional nessa área e com impactos significativos no mercado de trabalho ${ }^{31}$.

\section{CONCLUSÃO}

Dentro dos limites do presente estudo, conclui-se que a abordagem pedagógica sobre biossegurança no curso de Odontologia da UVFJM deve ser revista a modo de ampliar os assuntos abordados, capacitar melhor os alunos diante de situações de acidente e diminuir a distância entre o conhecimento teórico e a prática, formando profissionais com o pensamento crítico para uma prática odontológica ética e segura. Conclui-se também que é importante o investimento em capacitação dos profissionais, não só da área de ensino, melhorando os resultados com os graduandos, como todos os envolvidos no curso de Odontologia, como técnicos e funcionários da limpeza, visto que o tema biossegurança é importantíssimo para a segurança do trabalho.

\section{ABSTRACT}

Introduction: Biosafety is a key issue in dentistry considering the procedures in the professional and the work team come in contact with secretions from the oral cavity, potentially contaminating. Objective: To evaluate the biosafety knowledge of teachers, technicians, students and employees responsible for cleaning clinics and laboratories of the course of Dentistry UFVJM. Methodology: A qualitative and quantitative research was carried out using four validated questionnaires, one for each target group of those involved. Results: In total, were evaluated questionnaires answered by 156 students, 17 technicians, 19 teachers and 7 employees cleaning. From the results, it is observed that $84.2 \%$ of teachers report that address biosafety, however, $31.6 \%$ of teachers believe that students are not aware of biosafety. $42.9 \%$ of the cleaning staff do not know what is biosafety, $100 \%$ received no training and would like to receive more information. Among the technicians of the Department of Dentistry, $64.7 \%$ did not receive prior training and only $11.8 \%$ receive periodic training to prevent accidents. Among the students, $48.7 \%$ believe that education is insufficient for safe clinical practice, $17.9 \%$ do not use PPE complete, $55.8 \%$ of students would not know how to behave in front of an accident with contaminated material, although $25.6 \%$ report that have suffered an accident. Conclusion: The pedagogical approach on biosafety in the Dentistry course should be revised to better enable students and bridge the gap between theoretical knowledge and practice. It is necessary to invest in training of all professional staff involved in the course of Dentistry. 


\section{KEYWORDS}

Forensic Dentistry; Exposure to Biological Agents; Environmental Risks.

\section{REFERÊNCIAS}

1. Teixeira $P$, Valle $S$. Biossegurança: Uma abordagem multidisciplinar. Rio de Janeiro. Fundação Oswaldo Cruz,1996.

2. Brasil. Presidência da República. Lei no 8.974, de 5 de janeiro de 1995. Regulamenta os incisos II e V do $\S 1$ 으 do art. 225 da Constituição Federal, estabelece normas para o uso das técnicas de engenharia genética $e$ liberação no meio ambiente de organismos geneticamente modificados, autoriza o Poder Executivo a criar, no âmbito da Presidência da República, a Comissão Técnica Nacional de Biossegurança, e dá outras providências. Disponível em: http://www.planalto.gov.br/ccivil 03/LEl S/L8974.htm.

3. Pereira MEC, Costa MAF, Borba CM, Jurberg C. Construção do conhecimento em biossegurança: uma revisão da produção acadêmica nacional na área de saúde (19892009). Saúde e Sociedade. 2010; 19:395-404.

http://dx.doi.org/10.1590/S010412902010000200015.

4. Brasil. Presidência da República. Lei no 11.105, de 24 de março de 2005. Regulamenta os incisos II, IV e V do $\S$ $1^{\circ}$ do art. 225 da Constituição Federal, estabelece normas de segurança e mecanismos de fiscalização de atividades que envolvam organismos geneticamente modificados - OGM e seus derivados, cria o Conselho Nacional de Biossegurança - CNBS, reestrutura a Comissão Técnica Nacional de Biossegurança - CTNBio, dispõe sobre a Política Nacional de
Biossegurança - PNB, revoga a Lei $n^{\circ}$ 8.974, de 5 de janeiro de 1995, e a Medida Provisória $n^{\circ} 2.191-9$, de 23 de agosto de 2001 , e os arts. $5^{\circ}, 6^{\circ}, 7^{\circ}, 8^{\circ}$, $9^{\circ}, 10$ e 16 da Lei $n^{\circ} 10.814$, de 15 de dezembro de 2003, e dá outras providências. Disponível em: http://www.planalto.gov.br/ccivil 03/ at o2004-2006/2005/lei/l11105.htm.

5. Costa MAF, Costa MFB. Biossegurança de OGM: uma visão integrada. Rio de Janeiro Publit, 2009.

6. Needlestick transmission of HTLV-III from a patient infected in Africa. Lancet (London, $\quad$ England). 1984; 2(8416):1376-7. http://dx.doi.org/10.1016/S01406736(84)92065-8.

7. Santos NJS, Monteiro ALC, Ruiz EAC. The first case of AIDS due to occupational exposure in Brazil. Brazilian Journal of Infectious Diseases. 2002; 6:140-1. http://dx.doi.org/10.1590/S141386702002000300007.

8. Ferreira CT, Silveira TRD. Hepatites virais: aspectos da epidemiologia e da prevenção. Revista Brasileira de Epidemiologia. 2004; 7:473-87. http://dx.doi.org/10.1590/S1415790X2004000400010.

9. Gir E, Netto JC, Malaguti SE, Canini SRMS, Hayashida M, Machado AA. Accidents with biological material and immunization against hepatitis $B$ among students from the health area. Revista Latino-Americana de Enfermagem. 2008; 16:401-6. http://dx.doi.org/10.1590/S010411692008000300011. 
10. Brandão Júnior PS. Biossegurança e AIDS: as dimensões psicossociais do acidente com material biológico no trabalho em hospital. [Dissertação]. Rio de Janeiro. Escola Nacional de Saúde Pública, Fundação Oswaldo Cruz. 2000.

11. Silva JAD, Paula VSD, Almeida AJ, Villar LM. Investigação de acidentes biológicos entre profissionais de saúde. Escola Anna Nery. 2009; 13:508-16. http://dx.doi.org/10.1590/S141481452009000300008.

12. Marino CGG, El-Far F, Wey SB, Medeiros EAS. Cut and puncture accidents involving health care workers exposed to biological materials. Brazilian Journal of Infectious Diseases. 2001; 5:235-42. http://dx.doi.org/10.1590/S141386702001000500001.

13. Brasil. Ministério da Saúde. Agência Nacional de Vigilância Sanitária. Serviços odontológicos: prevenção e controle de riscos. Brasília, 2006.

14. Pinelli C, Garcia PPNS, Campos JÁDB, Dotta EAV, Rabello AP. Biossegurança e odontologia: crenças e atitudes de graduandos sobre 0 controle da infecção cruzada. Saúde e Sociedade. 2011;

20:448-61.

http://dx.doi.org/10.1590/S010412902011000200016.

15. Canini SRMS, Gir E, Machado AA. Accidents with potentially hazardous biological material among workers in hospital supporting services. Revista Latino-Americana de Enfermagem. 2005; 13:496-500.

http://dx.doi.org/10.1590/S010411692005000400006.

16. Bezerra ALD, Souza MNA, Feitosa ANA, Assis EV, Barros CMB, Carolino ECA. Biossegurança na odontologia. ABCS Health Sci. 2014; 39:29-33. http://dx.doi.org/10.7322/abcshs.v39i1. 251.

17. Brasil. Ministério da Educação. Universidade Federal dos Vales do Jequitinhonha e Mucuri. Conselho Universitário - CONSU. RESOLUÇÃO №. 21-CONSU, DE 01 DE JULHO DE 2011. Regimento Interno do Comitê de Ética em Pesquisa-CEP da Universidade Federal dos Vales do Jequitinhonha e Mucuri-UFVJM. Diamantina, 2011

18. Araújo MM. Validação semântica e ética de questionários para avaliação das práticas de biossegurança entre discentes e técnicos do curso de odontologia/UFVJM [trabalho de conclusão de curso] Diamantina: Faculdade de Farmácia da Universidade Federal dos Vales do Jequitinhonha e Mucuri; 2012.

19. Díaz-Tamayo AM, Vivas MC. Riesgo biológico y prácticas de bioseguridad en docencia. Rev Fac Nac Salud Pública. 2016; 34(1): 62-9. http://dx.doi.org/10.17533/udea.rfnsp.v 34n1a08.

20. Lages SMR, Santos AF, Silva Junior FF, Costa GJ. Formação em odontologia: O papel das instituições de ensino na prevenção do acidente com exposição a material biológico. Ciencia \& Trabajo. 2015; 17:182-7. http://dx.doi.org/10.4067/S071824492015000300005.

21. Oliveira JS, Nery AA, Morais RLGL, Robazzi MLCC. Acidentes com perfurocortante entre trabalhadores de saúde. Rev APS. 2015; 18(1):108-15.

22. Barros DX, Franco LC, Tipple AFV, Barbosa MA, Silva e Souza AC. Exposição a material biológico no manejo externo dos resíduos de Serviço de saúde. Cogitare Enferm. 2010; 15(1):82-6. 
23. Discacciati JAC, Vilaça ÊL. Atendimento odontológico ao portador do HIV: medo, preconceito e ética profissional. Revista Panamericana de Salud Pública. 2001; 9:234-9. http://dx.doi.org/10.1590/S102049892001000400005.

24. Conselho Federal de Odontologia (CFO). Código de Ética Odontológica: resolução n. 118. Rio de Janeiro: CFO; 2012.

25. Discacciati JAC. Disposição de cirurgiões dentistas para atender indivíduos em risco para a infecção pelo HIV ou com AIDS. [dissertação] Belo Horizonte. Faculdade de Odontologia da Universidade Federal de Minas Gerais; 1997.

26. Garbin AJI, Garbin CAS, Arcieri RM, Crossato M, Ferreira NF. Biosecurity in public and private office. J Applied Oral Sci. 2005; 13:163-6. http://dx.doi.org/10.1590/S167877572005000200013.

27. Jorge AOC. Princípios de biossegurança em odontologia. Rev Biociênc. 2002;8(1):7-17

28. Ferreira EL. Controle de Infecção e Biossegurança. Procedimentos Operacionais Padrão. CRO-Paraná. 2012.

29. Godoi APT, Francesco AR, Duarte A, Kemp APT, Silva-lovato $\mathrm{CH}$. Odontologia hospitalar no Brasil. Uma visão geral. Rev Odontol UNESP. 2009; 38(2):105-9.

30. Neves TP, Cortez EA, Moreira CO. Biossegurança como ação educativa: contribuições à saúde do trabalhador. Cogitare Enfermagem. 2006; 11:50-54. http://dx.doi.org/10.5380/ce.v11i1.5978.

31. Costa MAF. Construção do conhecimento em saúde: o ensino de biossegurança em cursos de nível médio na Fundação Oswaldo Cruz.
[Tese]. Rio de Janeiro. Instituto Oswaldo Cruz da Fundação Oswaldo Cruz, 2005. 